\title{
Characterization of envelope proteins from Pasteurella haemolytica and Pasteurella multocida
}

\author{
J. M. KNIGHTS, ${ }^{1 *}$ C. AdLAM ${ }^{1}$ and P. OWEN ${ }^{2}$ \\ ${ }^{1}$ Department of Molecular Biology, Wellcome Biotech, Wellcome Research Laboratories, Beckenham, Kent, UK \\ ${ }^{2}$ Department of Microbiology, Moyne Institute, Trinity College, Dublin, Eire
}

(Received 29 September 1989; revised 20 November 1989; accepted 30 November 1989)

\begin{abstract}
A method was devised for the reproducible isolation of envelopes from Pasteurella haemolytica serotype A2. It was also possible to prepare envelopes from other serotypes of $P$. haemolytica and Pasteurella multocida using this methodology. Examination of these preparations by SDS-PAGE showed major differences between strains of $P$. haemolytica and strains of $P$. multocida which allowed the clear distinction of isolates of these species. Amongst the $P$. haemolytica serotypes it was possible to distinguish envelope preparations made from $A$ biotype and $T$ biotype organisms easily, but it was not possible to identify individual serotypes from each other. Envelope profiles were sufficiently different between the individual $P$. multocida serotypes examined to allow each to be identified by its polypeptide profile. Experiments using radiolabelling, antibody absorption, and susceptibility to protease digestion, together with heat modifiability and detergent solubility characteristics indicated that 13 of the envelope proteins were probably surface-located. A high molecular mass immunogenic envelope protein was shown, by immunoblotting, to be present in all strains of $P$. haemolytica and $P$. multocida examined.
\end{abstract}

\section{Introduction}

Pasteurella haemolytica is responsible for respiratory and septicaemic infections of cattle, sheep and goats. To date, 16 serotypes (Biberstein, 1978; Fodor et al., 1988) have been identified, belonging to two biotypes; A (majority arabinose-fermenting) and $\mathrm{T}$ (majority trehalose-fermenting). Serotyping depends on the presence of surface capsular polysaccharides, and to date five of these have been purified and characterized (Adlam et al., 1984, 1985a, 1985b, 1986, 1987).

Prevention of pneumonic pasteurellosis is at present effected by vaccination using formalin-killed whole-cell vaccines, extracts of whole cells or live attenuated vaccines. Protection with current vaccines is variable, with little or no protection being provided by extract vaccines against heterologous serotype challenge (Gilmour et al., 1983). Extract vaccines prepared from serotype A2 (the serotype of most importance in ovine pasteurellosis) have not proved useful, probably because of the poor immune response to the serotype-specific capsular polysaccharide, which is composed of sialic

Abbreviations: CBB, Coomassie Brilliant Blue; KDO, 2-keto-3deoxyoctonate (3-deoxy-D-manno-octulosonate); PMSF, phenylmethylsulphonyl fuoride; TLCK, $N$ - $\alpha$-p-tosyl-L-lysine chloromethyl ketone. acid, a common constituent of host membranes (Adlam et al., 1987). Development of a better vaccine giving protection against all serotypes might be facilitated by the identification of common antigens.

In the present study we have isolated and analysed the envelopes from several serotypes of $P$. haemolytica with a view to determining whether such common protein antigens exist. In addition, envelopes have been compared with those isolated from the related pathogen $P$. multocida. The putative surface location of envelope polypeptides has been inferred by their fractionation in sucrose density gradients, susceptibility to protease degradation, ability to be radiolabelled on intact organisms, heat modifiability, and reaction with immune antisera.

\section{Methods}

Reagents. All chemicals were of AnalaR grade and obtained from BDH unless otherwise stated.

Bacteria. Strains and serotypes of $P$. haemolytica and $P$. multocida used are given in Table 1. All bacteria were maintained freeze-dried in the Wellcome Culture Collection. In all cases serology was confirmed by taking single colonies of each strain and submitting them to passive haemagglutination (Biberstein, 1978). 
Table 1. Strains of $P$. haemolytica and P. multocida used

\begin{tabular}{ll}
\hline \hline Serotype* & \multicolumn{1}{c}{ Wellcome culture number } \\
\hline P. haemolytica & \\
A1 & $5492,7766,7770,7827$ \\
A2 & $358,832,4610,4676,7776,8439$ \\
T3 & $5494,6950,7800,8605$ \\
T4 & $5495,7801,7785$ \\
A5 & 5496,7837 \\
A6 & $5497,7775,7777,7778$ \\
A7 & $5498,7318,7768,7802$ \\
A8 & $5499,7803,8284$ \\
A9 & $5500,7773,7774,7767$ \\
T10 & $4596,4611,7804$ \\
A11 & 7806,7842 \\
A12 & $5503,7807,8332$ \\
A13 & 7844 \\
A14 & 7845 \\
T15 & 4598,8263 \\
$P$. multocida & \\
A & $5517,7826,8333$ \\
D & $4110,5523,5835,6864$ \\
E & $5518,5837,8146,8151$ \\
\hline \hline
\end{tabular}

* Serotyping was carried out by passive haemagglutination (Biberstein, 1978).

Growth of bacteria. Organisms were cultured for $15 \mathrm{~h}$ at $37^{\circ} \mathrm{C}$ in one litre of Pasteurella 7 broth (Wellcome) in two-litre conical flasks with orbital shaking (140 r.p.m.).

Radiolabelling of $P$. haemolytica cells. Cells were washed in $100 \mathrm{ml}$ $0.02 \mathrm{M}$-Tris/ $\mathrm{HCl}\left(\mathrm{pH} 7.8\right.$ ) at $4^{\circ} \mathrm{C}$ and centrifuged at $5000 \mathrm{~g}$ for $20 \mathrm{~min}$. The pellets were resuspended in $\sim 5 \mathrm{ml} 0.02 \mathrm{M}-\mathrm{Tris} / \mathrm{HCl}(\mathrm{pH} \mathrm{7.8)}$ ) and kept on ice prior to labelling with ${ }^{125} \mathrm{I}$ as follows. Fifty Iodobeads (Pierce and Warriner) were incubated at room temperature with $5 \mu \mathrm{l}$ $\mathrm{Na}^{125}$ I (Amersham) $(250 \mu \mathrm{Ci} ; 9.25 \mathrm{MBq})$ and $995 \mu 10.02 \mathrm{M}$-Tris $/ \mathrm{HCl}$ (pH 7.8) for $5 \mathrm{~min}$ with occasional shaking. The bacterial suspension $(5 \mathrm{ml})$ was added to the Iodobeads and maintained on ice for $15 \mathrm{~min}$ with mixing. The cell suspension was removed by pipette and centrifuged at $6000 \mathrm{~g}$ for $10 \mathrm{~min}$. Cells were washed three times with $5 \mathrm{ml} 0.02 \mathrm{M}$-Tris/ $\mathrm{HCl}\left(\mathrm{pH} \mathrm{7.8)}\right.$ to remove excess ${ }^{125} \mathrm{I}$, prior to resuspension in $2 \mathrm{ml}$ of this buffer.

Protease treatment of $P$. haemolytica cells. Cells were resuspended in $10 \mathrm{ml}$ portions of $10 \mathrm{mM}-\mathrm{Tris} / \mathrm{HCl}\left(\mathrm{pH} \mathrm{7.8)}\right.$ and incubated at $37^{\circ} \mathrm{C}$ with protease (proteinase $\mathrm{K}, 40 \mu \mathrm{g} \mathrm{ml}^{-1}$, or trypsin, $200 \mu \mathrm{g} \mathrm{ml}^{-1}$ ). After $1 \mathrm{~h}$ the reaction was terminated by addition of phenylmethylsulphonyl fluoride (PMSF, Sigma; for proteinase K treated cells) or $N$ - $\alpha$-p-tosyl-Llysine chloromethyl ketone (TLCK ; for trypsin treated cells) to a final concentration of $0.02 \mathrm{M}$. The mixture was centrifuged for $20 \mathrm{~min}$ at $20000 \mathrm{~g}$ at $4{ }^{\circ} \mathrm{C}$ and the pellet resuspended in $0.2 \mathrm{M}$ - Tris $/ \mathrm{HCl}$ buffer (pH 7.8) containing 0.01 $\mathrm{M}$-EDTA and $0.005 \mathrm{M}$ each of PMSF and TLCK, prior to preparation of envelopes from the cells by the standard method.

Protease treatment of envelope preparations. Envelope preparations suspended in $0.01 \mathrm{M}$ - Tris $/ \mathrm{HCl}$ ( $\mathrm{pH} 7.8$ ) containing 0.005 M-EDTA were incubated at $37^{\circ} \mathrm{C}$ with protease (proteinase $\mathrm{K}, 40 \mu \mathrm{g} \mathrm{ml}^{-1}$ or trypsin, $2 \%$ of total protein). After $1 \mathrm{~h}$ the reaction was terminated by adjusting to $0.02 \mathrm{M}$ with PMSF or TLCK. The mixture was centrifuged for $1 \mathrm{~h}$ at $150000 \mathrm{~g}$ at $4{ }^{\circ} \mathrm{C}$, the pellet resuspended in $0.01 \mathrm{M}-\mathrm{Tris} / \mathrm{HCl}(\mathrm{pH} 7.8)$ containing $0.005 \mathrm{M}$-EDTA and $0.002 \mathrm{M}$ of PMSF and TLCK and stored at $-40{ }^{\circ} \mathrm{C}$.
Isolation of bacterial envelopes. Envelopes were prepared from bacteria grown in Pasteurella 7 broth using a modification of the Witholt method (Witholt et al., 1976). Cells were harvested by centrifugation for $20 \mathrm{~min}$ at $4{ }^{\circ} \mathrm{C}$ and $6000 \mathrm{~g}$. The pellet was resuspended in $200 \mathrm{~mm}$-Tris/HCl (pH 7.8), $10 \mathrm{~mm}$-EDTA, $4 \mathrm{mM}^{-}$ PMSF containing lysozyme (200 mg ml-1) and DNAase I and RNAase (each at $10 \mu \mathrm{g} \mathrm{ml}^{-1}$ ) and incubated at $37^{\circ} \mathrm{C}$ for $90 \mathrm{~min}$. The suspension was then diluted with three vols cold distilled water and centrifuged twice for $20 \mathrm{~min}$ at $4{ }^{\circ} \mathrm{C}$ and $6000 \mathrm{~g}$. The resulting supernatant was recentrifuged for $1 \mathrm{~h}$ at $4^{\circ} \mathrm{C}$ and $150000 \mathrm{~g}$. The pellet was then washed twice in $10 \mathrm{~mm}$-Tris/ $\mathrm{HCl}$ (pH 7.8), $10 \mathrm{~mm}$-EDTA, 2 mM-PMSF by centrifugation for $1 \mathrm{~h}$ at $4{ }^{\circ} \mathrm{C}$ and $150000 \mathrm{~g}$. The washed envelope pellet was finally resuspended in a minimal amount of $0.01 \mathrm{M}$-Tris/HCl (pH 7.8) containing $5 \mathrm{mM}$-EDTA and $0.001 \mathrm{M}$-PMSF and either used immediately or stored at $-20^{\circ} \mathrm{C}$.

Fractionation of envelope preparations. (i) Sucrose density gradient centrifugation. Envelopes ( $\sim 3 \mathrm{mg}$ protein) were applied to the top of a continuous sucrose density gradient $(55-30 \%, \mathrm{w} / \mathrm{w}$, sucrose, total gradient volume $19 \mathrm{ml}$ ) and centrifuged for $18 \mathrm{~h}$ at $100000 \mathrm{~g}$ at $4{ }^{\circ} \mathrm{C}$. Fractions $(1.5 \mathrm{ml})$ were collected from the base of the tube using a peristaltic pump. Sucrose concentrations were estimated by refractometry.

(ii) Extraction with Triton $X-100$. Each envelope sample was extracted once with $0.01 \mathrm{M}$-Tris $/ \mathrm{HCl}(\mathrm{pH} 7.2)$ containing $2 \%(\mathrm{v} / \mathrm{v})$ Triton $\mathrm{X}-100$ and $0.01 \mathrm{M}-\mathrm{MgCl}_{2}$ (Schnaitman, 1973). Treated samples were allowed to stand for $15 \mathrm{~min}$ at room temperature before centrifugation for $20 \mathrm{~min}$ at $50000 \mathrm{~g}$. The pellets were resuspended in $0.01 \mathrm{M}-\mathrm{Tris} / \mathrm{HCl}$ (pH 7.2) containing 0.005 M-EDTA and 0.002 M-PMSF.

Biochemical assays. Protein was estimated by the method of Lowry or by measuring $\boldsymbol{A}_{\mathbf{2 8 0}}$, using a standard of bovine serum albumin (Sigma).

Protein in sucrose density gradient fractions was precipitated prior to assay, by addition of $10 \%(w / v)$ trichloroacetic acid (Sigma). The precipitate was resuspended to the original fraction volume in distilled water. Fractions were assayed for 2-keto-3-deoxyoctonate (KDO) by the method of Osborn (1963) and for reduced NADH dehydrogenase activity by the method of Osborn et al. (1972).

SDS-PAGE. This was done by the method of Laemmli (1970) using $12.5 \%(\mathrm{w} / \mathrm{v})$ acrylamide gels. Gels were stained overnight using $0.05 \%$ (w/v) Coomassie Brilliant Blue R (CBB) dissolved in a mixture of methanol/distilled water/glacial acetic acid $(9: 9: 2$, by vol.). Destaining was performed in the same solvent (without CBB).

Autoradiographs. Where appropriate, gels were dried using a heated $\left(80^{\circ} \mathrm{C}\right)$ slab-gel drier (Bio-Rad) attached to a vacuum line. For autoradiography, dried gels were exposed to X-OMAT S X-Ray film (Kodak) for $20 \mathrm{~h}$ at $-70^{\circ} \mathrm{C}$. Autoradiographs were developed for $5 \mathrm{~min}$ in Phenisol (Ilford) developer (diluted $1: 4$ ) and fixed for $1 \mathrm{~min}$ in Kodafix (Kodak).

Studies of heat modifiability of envelope polypeptides. For routine analysis, samples of envelope preparations were heated in Laemmli sample buffer for $10 \mathrm{~min}$ at various temperatures $(30,40,50,60,70,80$ and $100^{\circ} \mathrm{C}$ ) before SDS-PAGE.

For more detailed studies, envelopes were heated at $30^{\circ} \mathrm{C}$ in Laemmli sample buffer and polypeptides were resolved by SDS-PAGE and stained with CBB. Bands thought to be heat modifiable were excised and extracted by electroelution. This was achieved by placing the excised bands in a dialysis sac positioned between the electrodes of an electroblotting apparatus. Electroelution in buffer containing $0.025 \mathrm{M}$-Tris, $0.192 \mathrm{M}$-glycine and $0.1 \%$ (w/v) SDS was performed at $20 \mathrm{~V}$ for $24 \mathrm{~h}$. Resulting samples were dialysed with distilled water for $24 \mathrm{~h}$ and lyophilized. The lyophilized samples were resuspended in Laemmli buffer, reheated for $10 \mathrm{~min}$ at $100^{\circ} \mathrm{C}$ and re-examined by SDS-PAGE. 
Western blotting. The method of Towbin et al. (1979) was used to transfer polypeptides from SDS-PAGE gels to nitrocellulose filters (pore size $0.45 \mu \mathrm{m}$; Sartorius). Transfers were performed at $0.11 \mathrm{~A}$ for $18 \mathrm{~h}$ at $20^{\circ} \mathrm{C}$. Immunoblots were maintained in phosphate-buffered saline (PBS; pH 7.2) composed of $0.15 \mathrm{M}-\mathrm{NaCl}, 0.0032 \mathrm{M}-\mathrm{Na}_{2} \mathrm{HPO}_{4}$ and $0.0015 \mathrm{M}-\mathrm{KH}_{2} \mathrm{PO}_{4}$, containing $0.5 \%(\mathrm{v} / \mathrm{v})$ Tween 20 (Sigma) to prevent non-specific binding of protein to the nitrocellulose.

Blots were incubated at room temperature for $2 \mathrm{~h}$ in primary antibody diluted $1: 100$ in PBS/Tween 20. Immunoblots were washed three times for $10 \mathrm{~min}$ in PBS/Tween 20. Bound antibody was detected following incubation for $2 \mathrm{~h}$ at room temperature in a solution of protein A conjugated to horseradish peroxidase (Sigma), diluted 1:300 in PBS/Tween 20. After washing in PBS/Tween 20, reacting antigens were visualized by incubation for $3 \mathrm{~min}$ at room temperature in freshly prepared 'developing' reagent consisting of $60 \mathrm{mg}$ 4-chloro-1-naphthol (dissolved in $10 \mathrm{ml}$ methanol), $90 \mathrm{ml}$ PBS/Tween 20 and $50 \mu \mathrm{l}(30 \%$, w/v) hydrogen peroxide. Immunoblots were photographed immediately following development.

Production of antisera. Antisera were raised in rabbits following multiple intradermal injections $(50 \mu \mathrm{l})$ of antigen. Injections were repeated at weekly intervals for four occasions. The antigen $(2 \mathrm{mg}$ $\mathrm{ml}^{-1}$ ) was dissolved in $0.15 \mathrm{M}-\mathrm{NaCl}$ and emulsified with an equal volume of incomplete Freund's adjuvant (Wellcome). Three weeks after the final vaccination, rabbits were anaesthetized and exsanguinated.

Purification of immunoglobulins. All sera were processed as described by Owen (1985). Briefly, immunoglobulins were precipitated by the addition of ammonium sulphate $(25 \mathrm{~g}$ per $100 \mathrm{ml}$ serum). Precipitates were collected and dialysed against PBS (pH 7.2). The final volume of the immunoglobulin solution was adjusted to be one-tenth of the original serum volume.

Absorption of antisera. Sera were absorbed for $1 \mathrm{~h}$ at $20^{\circ} \mathrm{C}$ using various amounts of live bacteria $\left(1-8 \times 10^{12}\right.$ cells) or envelopes isolated by the standard procedure. These were then removed by centrifugation for $20 \mathrm{~min}$ at $6000 \mathrm{~g}$ for cells and $1 \mathrm{~h}$ at $50000 \mathrm{~g}$ for envelopes.

\section{Results}

\section{Isolation of envelopes}

A suitable method for the preparation of envelopes from $P$. haemolytica (see Methods) was developed after optimization of spheroplast formation by adjustment of EDTA and lysozyme concentrations. Experiments (not shown) to optimize spheroplast lysis and involving the use of the French pressure cell, sonication and osmotic shock showed that the osmotic shock procedure was the most convenient and reproducible method. Thus, when a French pressure cell was used, poor separation was achieved, with an apparent loss of putative innermembrane material. Sonication was more successful but results varied between experiments. SDS-PAGE analysis of typical A2 serotype envelopes prepared by osmotic shock as described in Methods is shown in Fig. 1. The polypeptide bands were numbered and their respective molecular masses calculated with reference to a panel of protein standards (Bio-Rad; see Table 2).

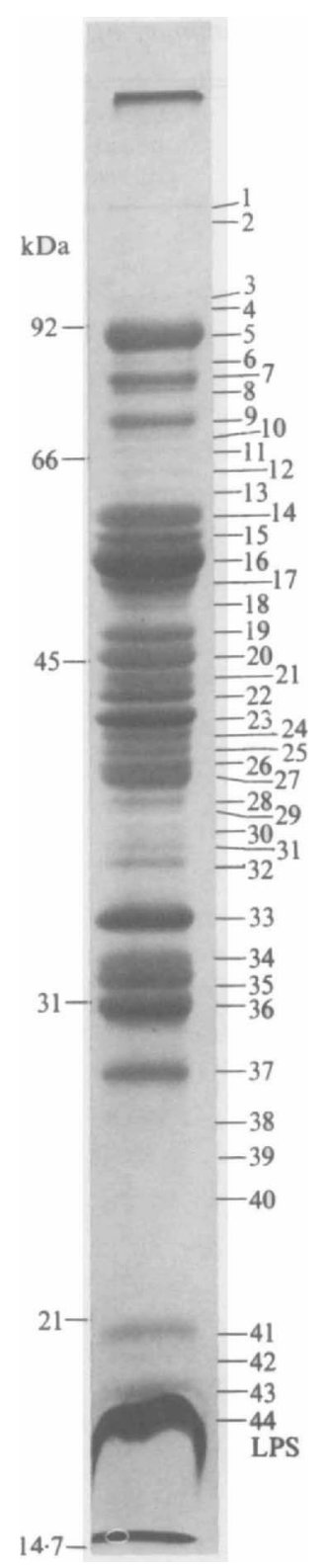

Fig. 1. CBB-stained SDS-polyacrylamide gel of a typical envelope preparation isolated from $P$. haemolytica A2 serotype (CN 8439). Track contains $70 \mu \mathrm{g}$ protein. Labels on the right-hand side show polypeptides separable by this technique (see Table 2). Positions of molecular mass standards are indicated on the left-hand side.

The same isolation techniques gave reproducible envelope preparations from other serotypes of $P$. haemolytica and P. multocida.

\section{Comparison of envelope profiles from $P$. haemolytica and P. multocida}

Envelopes isolated from different serotypes of $P$. haemolytica and $P$. multocida were compared by SDSPAGE (Fig. 2). Different isolates of the same serotype 
Table 2. Summary of SDS-PAGE polypeptide profile of a typical A2 serotype envelope preparation

\begin{tabular}{|c|c|c|c|c|c|c|c|}
\hline $\begin{array}{l}\text { Band } \\
\text { no. }\end{array}$ & $\begin{array}{c}\sim \text { Mol. } \\
\text { mass } \\
(\mathrm{kDa})\end{array}$ & $\begin{array}{c}\text { Sucrose } \\
\text { density } \\
\text { gradient* }\end{array}$ & $\begin{array}{c}\text { Triton } \mathrm{X}-100 / \mathrm{Mg}^{2+} \\
\text { solubility } \dagger\end{array}$ & ${ }^{125}$ I-radiolabelling $\ddagger$ & $\begin{array}{c}\text { Proteinase } \mathrm{K} \\
\text { treatment } \S\end{array}$ & $\begin{array}{c}\text { Trypsin } \\
\text { treatment } \S\end{array}$ & $\begin{array}{c}\text { Antibody } \\
\text { absorption } \|\end{array}$ \\
\hline 1 & $154 \cdot 5$ & + & I & - & d & d & - \\
\hline 2 & $141 \cdot 1$ & + & I & - & d & d & - \\
\hline 3 & 98.4 & + & I & - & $r$ & $\mathbf{r}$ & - \\
\hline 4 & $92 \cdot 3$ & + & I & * & $\mathbf{r}$ & d & + \\
\hline 5 & $89 \cdot 2$ & + & I & - & $\mathbf{r}$ & d & - \\
\hline 6 & $84 \cdot 0$ & + & I & - & $\mathbf{r}$ & d & - \\
\hline 7 & $80 \cdot 1$ & + & I & * & $\mathbf{r}$ & $\mathrm{p}$ & + \\
\hline 8 & $77 \cdot 3$ & - & I & - & $\mathrm{r}$ & d & - \\
\hline 9 & $72 \cdot 8$ & + & I & * & $\mathrm{r}$ & d & + \\
\hline 10 & $69 \cdot 4$ & + & I & - & $\mathrm{r}$ & $\mathrm{d}$ & - \\
\hline 11 & 66.9 & + & I & - & $\mathbf{r}$ & d & - \\
\hline 12 & $63 \cdot 8$ & + & I & - & $\mathrm{r}$ & d & - \\
\hline 13 & 61.5 & + & I & - & $\mathrm{r}$ & d & + \\
\hline 14 & $58 \cdot 7$ & $-1+$ & $\mathrm{i} / \mathbf{S}$ & - & $\mathrm{p}$ & $\mathrm{p}$ & + \\
\hline 15 & $56 \cdot 6$ & + & I & * & $\mathrm{r}$ & $\mathrm{p}$ & + \\
\hline 16 & $53 \cdot 7$ & $-1+$ & $\mathrm{I} / \mathrm{s}$ & ** & $\mathbf{r}$ & d & - \\
\hline 17 & $52 \cdot 0$ & + & I & - & $\mathrm{r}$ & $\mathrm{r}$ & - \\
\hline 18 & $49 \cdot 6$ & + & I & - & $\mathbf{r}$ & $\mathbf{r}$ & - \\
\hline 19 & $47 \cdot 2$ & - & $\mathrm{i} / \mathrm{S}$ & * & $\mathrm{r}$ & $\mathbf{r}$ & - \\
\hline 20 & 45.0 & $+1-$ & $\mathrm{I} / \mathrm{s}$ & - & $\mathbf{r}$ & $\mathbf{r}$ & - \\
\hline 21 & $44 \cdot 0$ & $+1-$ & $\mathrm{i} / \mathrm{S}$ & - & $\mathrm{r}$ & $\mathbf{r}$ & - \\
\hline 22 & $43 \cdot 5$ & + & I & $* *$ & $r$ & $r$ & - \\
\hline 23 & $42 \cdot 4$ & + & I & ** & $\mathrm{r}$ & $\mathrm{r}$ & + \\
\hline 24 & $41 \cdot 4$ & - & $\mathrm{i} / \mathrm{S}$ & - & $r$ & $r$ & - \\
\hline 25 & $40 \cdot 9$ & + & I & - & $r$ & $p$ & - \\
\hline 26 & $40 \cdot 0$ & + & I & - & $\mathrm{p}$ & $p$ & - \\
\hline 27 & 39.5 & $-1+$ & $\mathbf{S}$ & ** & $\mathrm{p}$ & $\mathrm{p}$ & - \\
\hline 28 & 38.5 & + & $\mathrm{i} / \mathbf{S}$ & - & $\mathrm{r}$ & $\mathrm{r}$ & - \\
\hline 29 & $38 \cdot 1$ & $-1+$ & $\mathrm{i} / \mathbf{S}$ & - & $\mathbf{r}$ & $r$ & + \\
\hline 30 & $37 \cdot 6$ & $-1+$ & S & $* *$ & $\mathrm{r}$ & d & + \\
\hline 31 & $36 \cdot 7$ & $-1+$ & I & - & d & d & + \\
\hline 32 & 35.9 & - & I & - & $\mathrm{r}$ & d & - \\
\hline 33 & 33.8 & + & I & ** & d & $\mathbf{r}$ & + \\
\hline 34 & $32 \cdot 6$ & + & I & $* *$ & d & $r$ & + \\
\hline 35 & 31.8 & + & $\mathbf{S}$ & * & d & $\mathrm{r}$ & + \\
\hline 36 & $30 \cdot 7$ & - & I & - & d & $\mathrm{p}$ & + \\
\hline 37 & $28 \cdot 2$ & - & $\mathrm{S}$ & - & $\mathrm{d}$ & $\mathrm{r}$ & + \\
\hline 38 & 26.9 & - & $\mathrm{S}$ & - & $\mathrm{r}$ & d & + \\
\hline 39 & 25.9 & - & $\mathrm{S}$ & - & $r$ & $r$ & - \\
\hline 40 & $24 \cdot 4$ & - & $S$ & - & $r$ & $\mathrm{r}$ & + \\
\hline 41 & $20 \cdot 4$ & + & I & ** & $r$ & $r$ & - \\
\hline 42 & $19 \cdot 4$ & + & I & ** & $r$ & $r$ & - \\
\hline 43 & 18.0 & + & I & $* *$ & $r$ & $r$ & - \\
\hline $\begin{array}{l}44 \text { in LPS } \\
\text { staining area }\end{array}$ & $<18.0$ & + & I & $* *$ & $\mathbf{r}$ & $\mathbf{r}$ & - \\
\hline
\end{tabular}

* Presence in fraction 4 of sucrose density gradient [this fraction was taken as a typical outer-membrane protein fraction (sp. gr. $=1 \cdot 21 \mathrm{~g}$ $\left.\mathrm{cm}^{-1}\right)$ ]. + , Polypeptide present; - , polypeptide absent; $+/-$, polypeptides of similar molecular mass but present in greater amounts in other sucrose fractions.

$\dagger \mathrm{I}$, Triton X-100/ $\mathbf{M g}^{2+-i n s o l u b l e ~(p u t a t i v e ~ o u t e r-m e m b r a n e ~ p r o t e i n) ; ~} \mathrm{~S}$, Triton X-100/ $\mathbf{M g}^{2+}$-soluble (putative inner-membrane protein; i/S, $\mathrm{I} / \mathrm{s}$, polypeptides of similar molecular mass found in both fractions but with the greater amount of polypeptide in the fraction represented with a capital letter.

$\ddagger^{* *}$, Strongly ${ }^{125}$ I-radiolabelled polypeptide; $*$, weakly ${ }^{125} \mathrm{I}$-radiolabelled polypeptide; -, no ${ }^{125}$ I-radiolabelling.

$\S$ Envelopes produced from cells treated with protease (proteinase $\mathrm{K}$ or trypsin) prior to envelope isolation. $\mathrm{r}$, Resistant to protease; $d$, degraded by protease; $p$, partially degraded by protease.

$\|$ Absorption of specific antibody from hyperimmune A2 envelope serum by live A2 serotype bacteria. + , Antibody absorbed from serum by A2 serotype bacteria; - , no antibody absorption.

had similar polypeptide profiles with the single exception of an A7 isolate (CN 5498; Fig. 2, track 7). This isolate produced a different envelope polypeptide profile in the $30-70 \mathrm{kDa}$ region to three other $\mathrm{A} 7$ isolates
(CN 7318, CN 7768 and CN 7802), which produced profiles similar to each other. The envelope profile of one of the typical A7 strains (CN 7768) is shown in Fig. 2, track 6. 


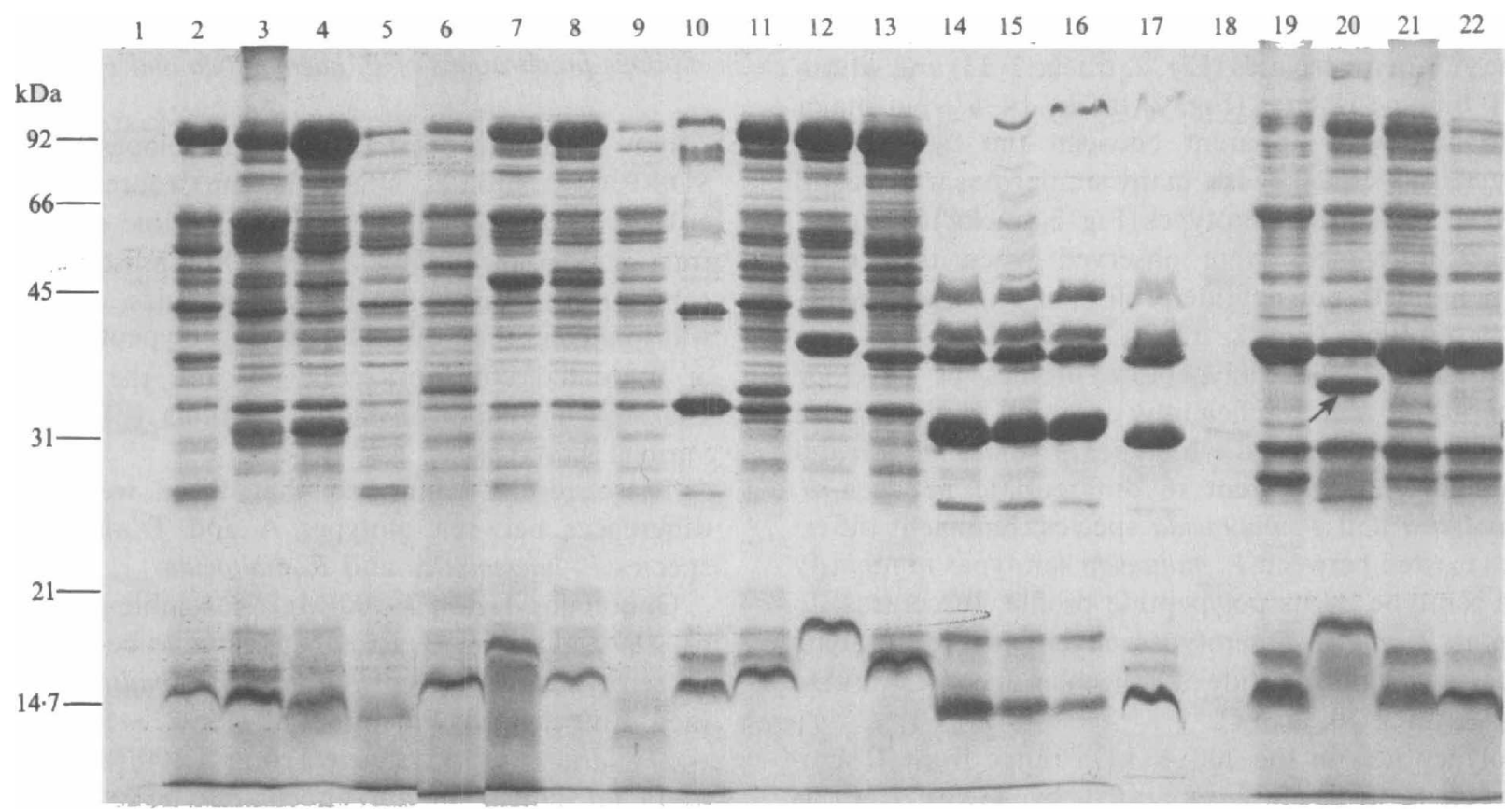

Fig. 2. SDS-PAGE of envelopes isolated from representative isolates of serotypes of $P$. haemolytica and $P$. multocida. Tracks 1 and 18 contain molecular mass standards. Remaining tracks are as follows. Tracks $2-17$, P. haemolytica: 2 , serotype A1;3, A2;4, A5;5, A6;6, A7 (CN 7768); 7, A7 (CN 5498); 8, A8; 9, A9; 10, A11; 11, A12; 12, A13; 13, A14; 14, T3; 15, T4; 16, T10; 17, T15. Tracks 19-22, P. multocida: 19 , serotype A; $20, \mathrm{~B} ; 21, \mathrm{D} ; 22$, E. All tracks were loaded with $60 \mu \mathrm{g}$ of protein. Arrow indicates polypeptide of $\sim 38.5 \mathrm{kDa}$ found in envelopes of $P$. multocida serotype $B$.

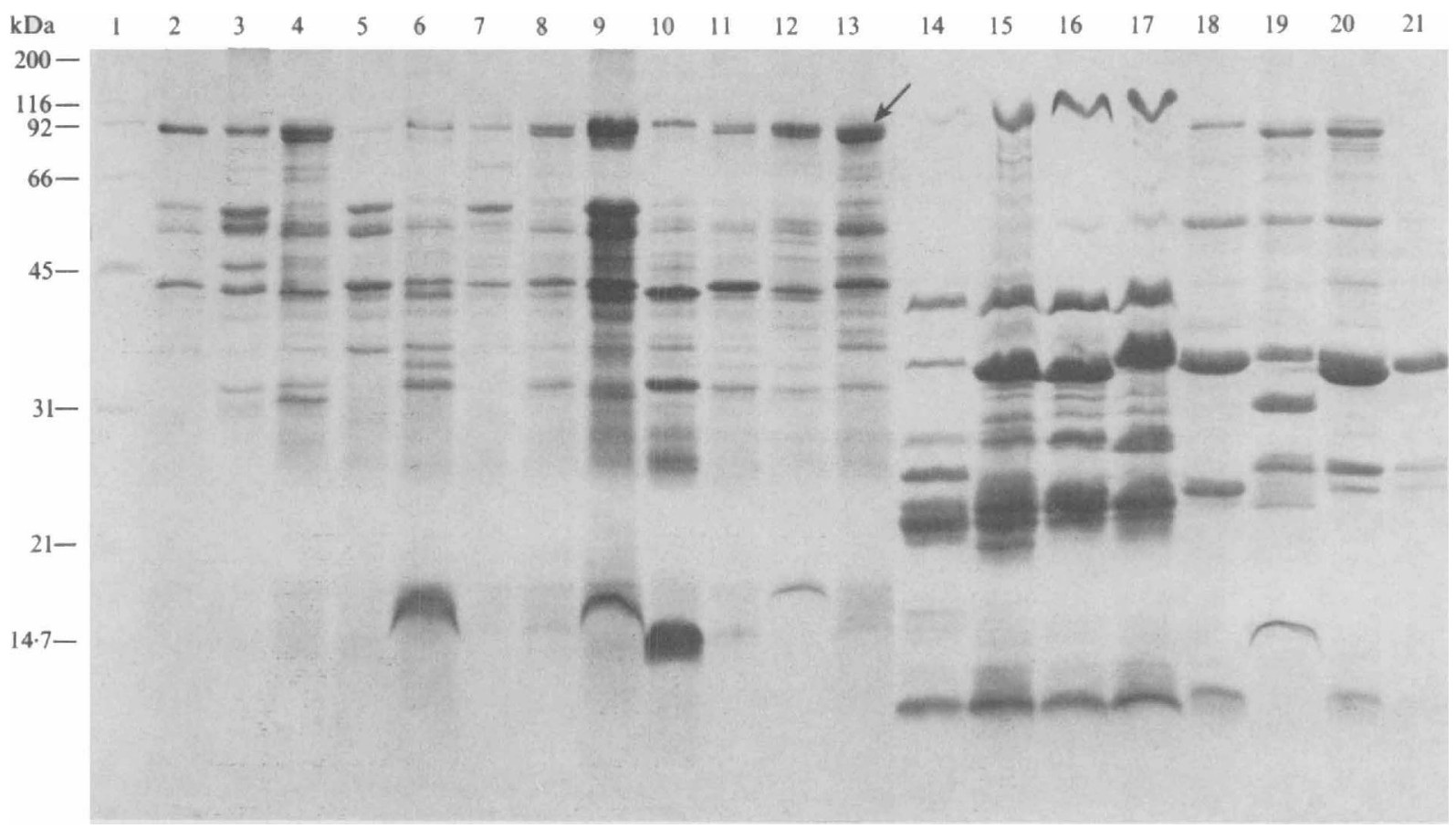

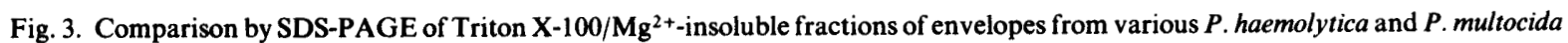
serotypes. Track 1 contains molecular mass standards. Remaining tracks are as follows. Tracks 2-17, P. haemolytica: 2, serotype A1; 3, A2;4, A5; 5, A6; 6, A7 (CN 5498); 8, A8; 9, A9; 10, A11;11, A12; 12, A13;13, A14; 14, T3; 15, T4; 16, T10; 17, T15. Tracks 18-21, P. multocida: 18, serotype A; 19, B; 20, D; 21 , E. All tracks were loaded with $50 \mu$ g protein. Arrow indicates Triton X-100/Mg ${ }^{2+-}$ insoluble polypeptide of $\sim 89.2 \mathrm{kDa}$ which is common to all $P$. haemolytica and $P$. multocida serotypes. 
Considerable qualitative similarities were noted within the A biotype isolates (Fig. 2, tracks 2-13) and within the $\mathrm{T}$ biotype isolates (Fig. 2, tracks 14-17) but major differences were apparent between the two sets of biotype isolates. Likewise, many similarities were found between $P$. multocida serotypes (Fig. 2, tracks 19-22), but distinct differences were observed when they were compared with polypeptide profiles of $P$. haemolytica A and $T$ serotypes (Fig. 2, tracks 2-17).

The SDS-PAGE polypeptide profiles of envelope preparations were sufficiently different to distinguish between $A$ biotypes and $\mathrm{T}$ biotypes of $P$. haemolytica and also sufficiently different to differentiate between $P$. haemolytica and P. multocida species. Sufficient differences existed between $P$. multocida serotypes to identify each serotype by its polypeptide profile. In contrast to the other $\boldsymbol{P}$. multocida serotypes, envelopes from serotype $B$ possessed a polypeptide of molecular mass $\sim 38.5 \mathrm{kDa}$ (Fig. 2, track 20, arrow).

Polypeptides in the $200-40 \mathrm{kDa}$ range from $\mathrm{T}$ serotypes were frequently separated by SDS-PAGE as diffuse or 'seagull' shaped bands (Fig. 2, tracks 14-17).
Comparison of Triton $\mathrm{X}-100 / \mathrm{Mg}^{2+}$-insoluble fractions of envelope preparations of $P$. haemolytica and $P$. multocida

Triton $\mathrm{X}-100 / \mathrm{Mg}^{2+}$ extraction of envelopes simplified SDS-PAGE profiles since the procedure separated envelope proteins into detergent insoluble and soluble fractions. In an attempt to detect the presence of any common or serotype-specific polypeptides, comparison was made between the SDS-PAGE polypeptide profiles of untreated envelopes (Fig. 2), and the Triton X$100 / \mathrm{Mg}^{2+}$-insoluble envelope fractions (Fig. 3) from various serotypes.

These results confirmed that there were distinct differences between biotypes $\mathrm{A}$ and $\mathrm{T}$ and between species $P$. haemolytica and $P$. multocida.

One major Triton X-100/ $\mathrm{Mg}^{2+}$-insoluble polypeptide of $\sim 89.2 \mathrm{kDa}$ (Fig. 3, arrow) appeared to be common to all serotypes of $P$. haemolytica and $P$. multocida examined. Five major polypeptides of $\sim 58.7, \sim 56.5, \sim 52.3$, $\sim 27 \cdot 8$, and $\sim 27 \cdot 1 \mathrm{kDa}$ were Triton $\mathrm{X}-100 / \mathrm{Mg}^{2+}$-soluble (data not shown) and also appeared to be common to all serotypes of $\boldsymbol{P}$. haemolytica and $\boldsymbol{P}$. multocida examined,

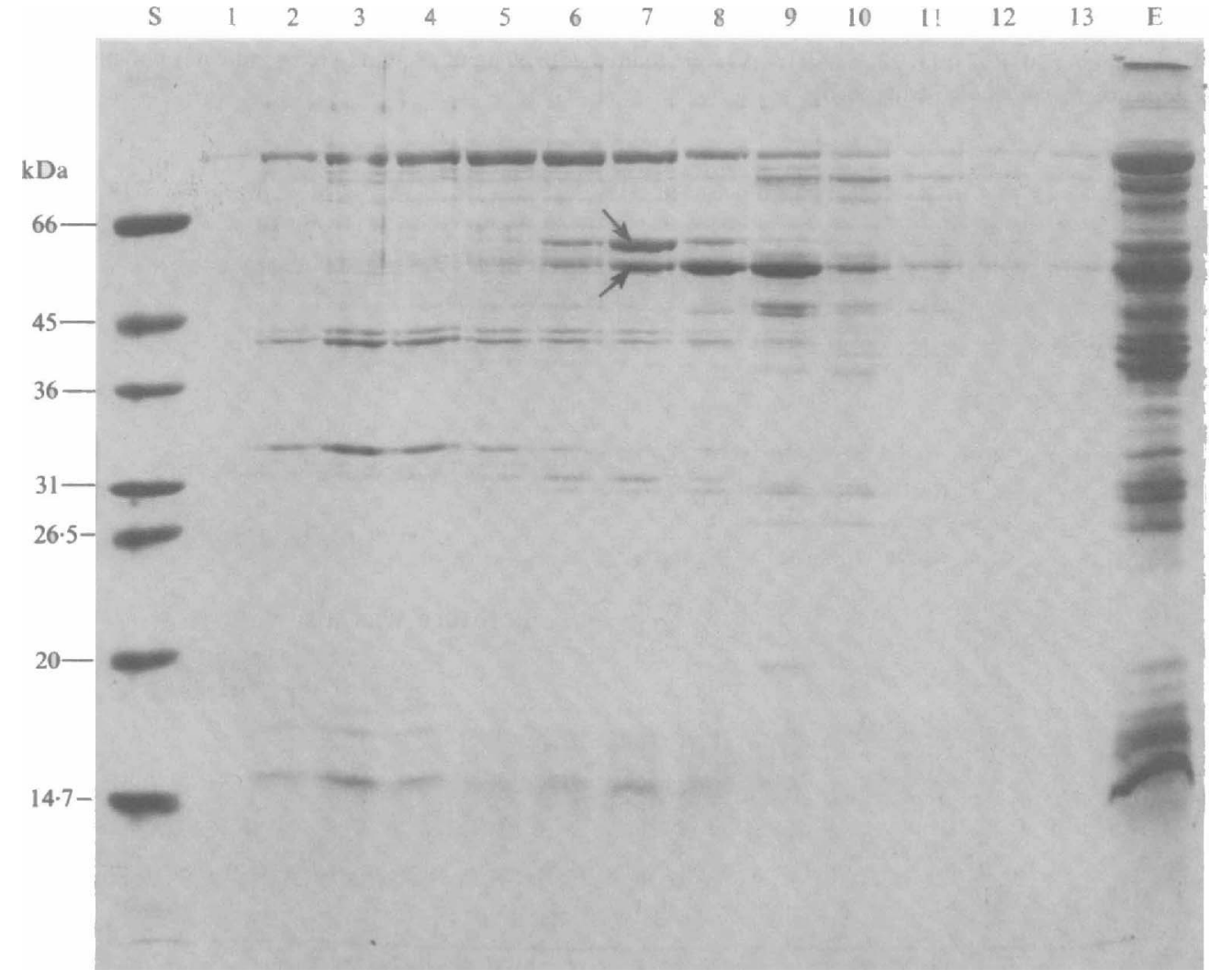

Fig. 4. SDS-PAGE of fractions obtained following ispycnic sucrose density gradient centrifugation of $P$. haemolytica serotype A2: (CN 8439) envelopes. Track S contains molecular mass standards. Track 1 contains fraction $1(54.7 \%$ sucrose $) ; 2$, fraction $2(52.7 \%)$; 3, fraction $3(48.4 \%)$; , fraction $4(45.0 \%)$; fraction $5(38.5 \%)$; 6 , fraction $6(38.5 \%)$; , fraction $7(37.4 \%) ; 8$, fraction $8(35.0 \%)$; 9 , fraction $9(32.7 \%) ; 10$, fraction $10(31.0 \%) ; 11$, fraction $11(26.5 \%) ; 12$, fraction $12(22.5 \%) ; 13$, fraction $13(22.0 \%)$. Each track was loaded with $60 \mu \mathrm{l}$ of the respective fraction. Track $\mathrm{E}$ contains $70 \mu \mathrm{l}$ of envelope protein. Arrows indicate two major polypeptides of $\sim 58.7$ and $\sim 53.7 \mathrm{kDa}$ found in all $P$. haemolytica $A$ serotypes. 
although there was quantitative variation of these bands between preparations.

\section{Fractionation of envelopes on sucrose density gradients}

Separation of envelope components by isopycnic sucrose density centrifugation into clearly defined fractions has been used as preliminary evidence for the probable location of envelope proteins (Osborn et al., 1973). The profile obtained when envelopes from A2 serotype organisms were fractionated in this way is shown in Fig. 4. Envelope proteins were clearly separable into three subfractions: putative outer-membrane proteins in fractions $1-5$, putative inner-membrane proteins in fractions $9-13$, and intermediate material in fractions $6-8$. The $\sim 89.2 \mathrm{kDa}$ polypeptide seemed to be found mainly in fractions 1-7 but could be detected in all fractions.

Sucrose density gradient fractionation of ${ }^{125}$ I-radiolabelled envelope preparations (data not shown) showed that, as expected, most of the radiolabelled polypeptides were found in that region of the gradient characteristic for outer-membrane proteins. For all $P$. haemolytica A serotypes examined, two major bands (Fig. 4, track 7, arrows) of $\sim 58.7$ and $\sim 53.7 \mathrm{kDa}$ were found predominantly in fractions 6-8 and 7-10 (specific gravity $1 \cdot 170$ 1.158 and $1.158-1.143 \mathrm{~g} \mathrm{~cm}^{-3}$ ), respectively, of the sucrose density gradients. The position of these two bands in the gradient might suggest an inner- rather than an outer-membrane location; this is further supported by their Triton $\mathrm{X}-100 / \mathrm{Mg}^{2+}$ solubility.

\section{Characterization of sucrose density gradient fractions}

Fractions obtained from the sucrose density gradient were characterized for their content of sucrose, protein, NADH dehydrogenase activity and KDO. Results of a typical experiment performed on A2 serotype envelopes are shown in Fig. 5. These results confirmed that a satisfactory separation of inner and outer membranes had been achieved, as gradient fractions with high KDO (an outer-membrane marker) content were fractions 1-7 inclusive. Those gradient fractions with highest NADH dehydrogenase (an inner-membrane marker) activity were fractions 12-14 inclusive.

Similar separations (data not shown) were obtained from isopycnic centrifugations of envelopes from all of the other serotypes of $\boldsymbol{P}$. haemolytica.

\section{Studies of heat modifiability of envelope proteins}

Analysis by SDS-PAGE of an A2 envelope preparation heated at various temperatures in Laemmli buffer showed that the migration of several polypeptides was

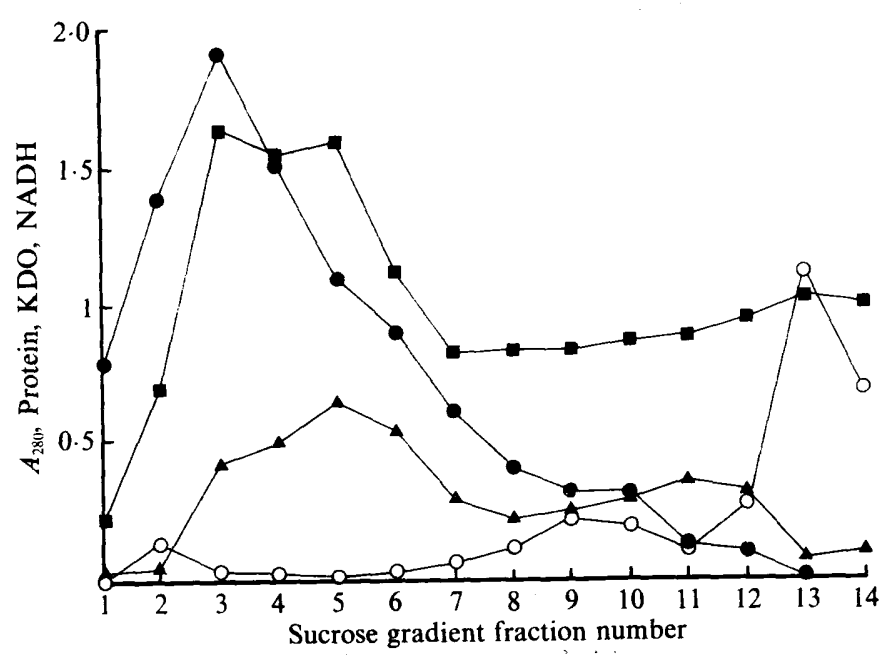

Fig. 5. Results of assays on sucrose density gradient fractions obtained following isopycnic centrifugation of envelopes from $P$. haemolytica serotype A2. $A_{280} ; \Delta$, amount of protein $\left(\mathrm{mg} \mathrm{ml}^{-1}\right) ; 0,100 \times$ concn of KDO (mg ml $\left.{ }^{-1}\right) ; \odot$, concn of NADH [mM (mg protein) $\left.)^{-1}\right]$.

temperature dependent (Fig. 6). Several new bands (arrowheads) appeared in the $100^{\circ} \mathrm{C}$-heated profile compared with the profile from envelopes incubated at $30^{\circ} \mathrm{C}$.

A major polypeptide of molecular mass $\sim 160 \mathrm{kDa}$ (track 2, arrow) was only present in samples heated below $40^{\circ} \mathrm{C}$. To ascertain the apparent molecular mass of this component when heated to $100{ }^{\circ} \mathrm{C}$, the band was excised, heated to $100{ }^{\circ} \mathrm{C}$ and reexamined by SDSPAGE. The excised polypeptide now migrated as a major polypeptide with an apparent molecular mass of $\sim 53.7 \mathrm{kDa}$ (Fig. 6; track 8, arrow). Minor polypeptides with molecular masses of $\sim 92.3$ and $\sim 43.5 \mathrm{kDa}$ were also observed in this electroeluted material.

Another polypeptide of $\sim 43.5 \mathrm{kDa}$ was prominent at temperatures $>60^{\circ} \mathrm{C}$ (Fig. 6, track 7 , arrow). An increase in staining of some other bands with increasing temperature was also noted (arrowheads). In part, this might reflect the different solubilities of proteins in Laemmli buffer at the different temperatures.

\section{Triton $/ \mathrm{Mg}^{2+}$-extraction of radiolabelled envelopes}

Experiments were done to assess the solubility of envelope polypeptides in a detergent, Triton X-100. Envelopes prepared from ${ }^{125} \mathrm{I}$-radiolabelled cells of $P$. haemolytica serotype A2 were extracted with Triton X$100 / \mathrm{Mg}^{2+}$ buffer. The envelope preparation prior to detergent treatment (Fig. 7, tracks 1 and 4), the Triton X$100 / \mathrm{Mg}^{2+}$-insoluble residue (track 2 ) and the Triton $\mathrm{X}$ $100 / \mathrm{Mg}^{2+}$-soluble fraction (track 3 ) were compared by 


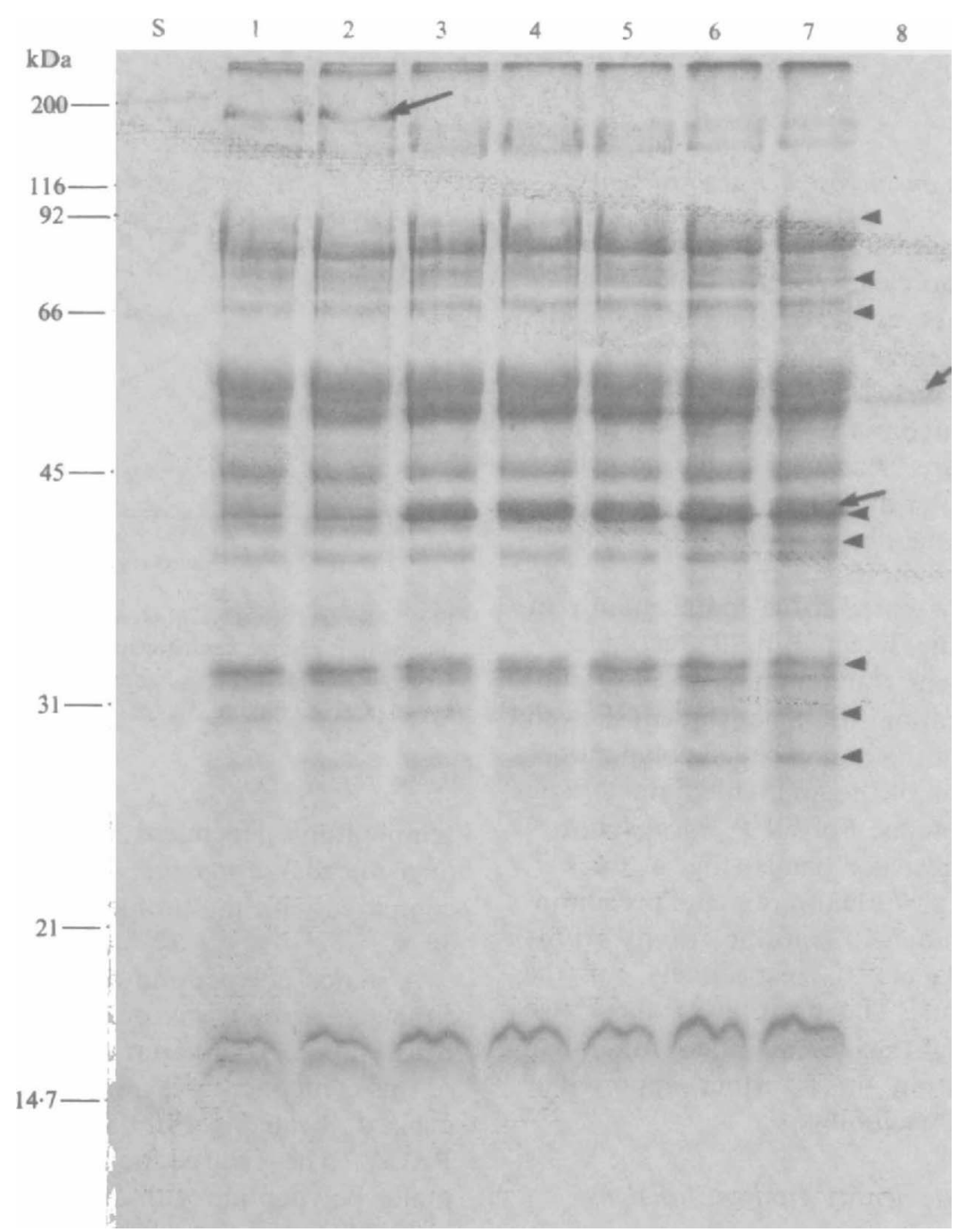

Fig. 6. SDS-PAGE of $A 2$ envelopes heated at various temperatures prior to electrophoresis. Track $\mathbf{S}$ contains molecular mass standards. Tracks $1-7, \mathrm{~A} 2$ envelopes heated for $10 \mathrm{~min}$ at $30^{\circ} \mathrm{C}$; various temperatures: track $1,2,40^{\circ} \mathrm{C} ; 3,50^{\circ} \mathrm{C} ; 4,60^{\circ} \mathrm{C} ; 5,70{ }^{\circ} \mathrm{C} ; 6$, $80^{\circ} \mathrm{C} ; 7,100^{\circ} \mathrm{C} ; 8$, excised polypeptide (apparent molecular mass $160 \mathrm{kDa}$ ) heated at $100^{\circ} \mathrm{C}$. Tracks $1-7$ were loaded with $60 \mu \mathrm{g}$ of protein and track 8 was loaded with $10 \mu \mathrm{g}$ of protein. See text for explanation of arrows.

SDS-PAGE, in conjunction with CBB staining (Fig. 7a) and autoradiography (Fig. $7 b$ ). Sixteen bands with varying levels of ${ }^{125} \mathrm{I}$ incorporation were observed. Of these bands, 13 appeared insoluble in Triton $\mathrm{X}$ $100 / \mathrm{Mg}^{2+}$. Two major and one minor radiolabelled polypeptides were found in the Triton X-100/ $\mathrm{Mg}^{2+}$ soluble fraction. Summary data are given in Table 2 .

The supernatant produced after centrifugation of the cell-free cell lysate at $150000 \mathrm{~g}$ showed little radiolabelling apart from two bands $(\sim 42.4$ and $\sim 28.2 \mathrm{kDa})$ which seemed to correspond to ${ }^{125}$ I-labelled envelope polypeptides also found in the Triton $\mathrm{X}-100 / \mathrm{Mg}^{2+}$-insoluble fraction. This would argue against significant cell lysis occurring during the labelling procedure.
Effect on envelope polypeptide profile of treatment of $A 2$ serotype cells with proteolytic enzymes

Treatment of cells with proteases followed by isolation of envelopes by the standard method was used as an alternative procedure to assess surface expression of polypeptides. This method yielded simpler envelope profiles (Fig. 8, tracks 2 and 3) than that produced from untreated cells (Fig. 8, track 1). Control experiments (data not shown) demonstrated that isolated envelope proteins were completely degraded with the exception of bands of 43.5 and $19.4 \mathrm{kDa}$.

Cells treated with proteinase $\mathrm{K}$ showed a different profile of degradation than those treated with trypsin. 
(a)

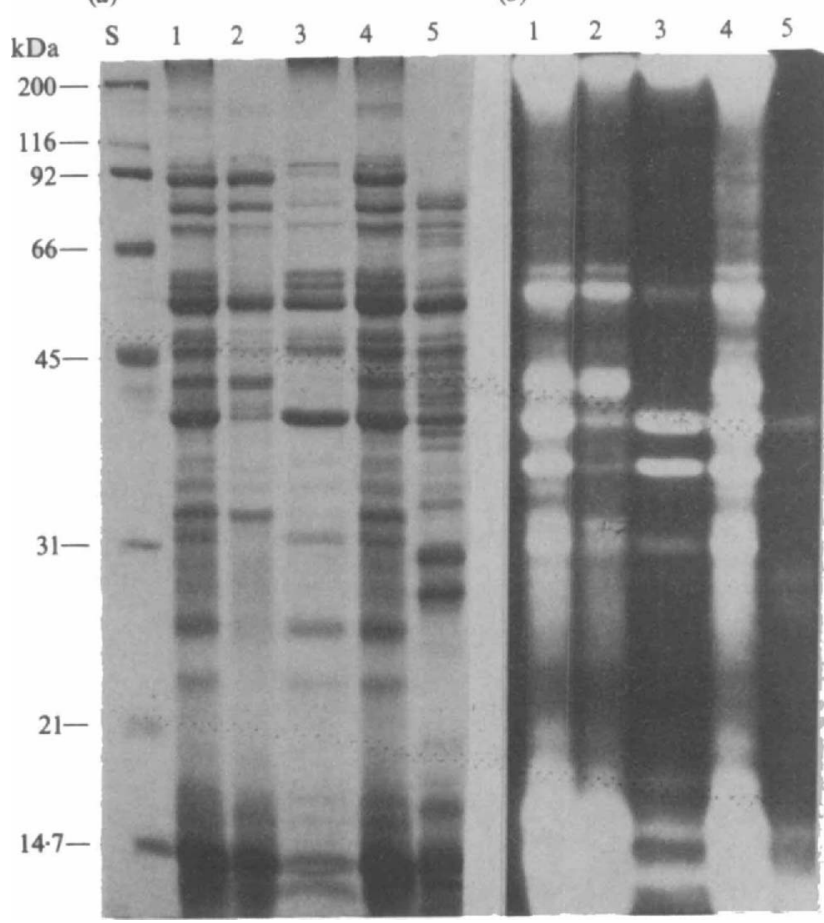

Fig. 7. SDS-PAGE examination of the solubility in Triton X-100/ $\mathrm{Mg}^{2+}$ of envelope polypeptides prepared from ${ }^{125}$ I-radiolabelled cells. (a) CBB-stained polyacrylamide gel, (b) direct autoradiograph of (a). Track S contains molecular mass standards. Track 1, envelopes isolated from ${ }^{125}$ I-radiolabelled cells; 2 , Triton X-100/ $\mathrm{Mg}^{2+}$-insoluble fraction of envelopes isolated from ${ }^{125}$ I-radiolabelled cells; 3, Triton X-100/ $\mathbf{M g}^{2+}$-soluble fraction of envelopes isolated from ${ }^{125} \mathrm{I}$-radiolabelled cells; 4, envelopes isolated from ${ }^{125}$ I-radiolabelled cells; 5, post-lysis supernatant following centrifugation at $150000 \mathrm{~g}$ for $1 \mathrm{~h}$. All tracks were loaded with $60 \mu \mathrm{g}$ of protein except tracks 2 and 3, loaded with material derived from $60 \mu \mathrm{g}$ envelope protein.

Polypeptides that were completely removed by proteinase $\mathbf{K}$ action were those having molecular masses of $\sim 154,141,98.4$ and $36.7 \mathrm{kDa}$ and those in the 32.6$28.2 \mathrm{kDa}$ range (summarized in Table 2). Some reduction also occurred in the intensity of a band of $\sim 58.7 \mathrm{kDa}$. New bands which appeared in the profile at $\sim 70,36,29$ and $27 \mathrm{kDa}$ were presumed to result from proteolytic action.

Similar experiments conducted with trypsin demonstrated that certain envelope polypeptides in the 90$60 \mathrm{kDa}$ region were completely removed. The heavily stained band seen in track 3 of Fig. 8 was probably derived from proteolytic digestion and represents a reinforcement of the weaker staining band of $43.5 \mathrm{kDa}$ seen in the untreated profile (track 1). Polypeptides of $\sim 52-41.4 \mathrm{kDa}$ and $\sim 38.5,38 \cdot 1,33 \cdot 8,31.8 \mathrm{kDa}$, and low molecular mass bands at $28-18 \mathrm{kDa}$ were largely unaffected by trypsin action, and, in contrast, polypeptides in the $37-35 \mathrm{kDa}$ region were almost completely removed.
The combined results of these experiments indicated that bands of $\sim 43.5,42.4,19.4$ and $18.0 \mathrm{kDa}$ probably corresponded to proteins which are surface-located and resistant to proteolytic action, whilst bands of 154,141 , 98.4 and $36.7 \mathrm{kDa}$, as well as several minor bands of molecular mass 70-80 kDa, are probably surface-located and susceptible to protease degradation.

\section{Reaction of envelope proteins with immune serum previously absorbed with $A 2$ serotype cells}

Immunoblotting experiments were conducted using A2 envelopes and both control anti-A2 envelope serum (Fig. 9, tracks 1 and 6) and identical serum which had been absorbed with differing concentrations of bacteria (tracks 2-5).

Progressive absorption of A2 envelope antiserum with increasing numbers of live A2 serotype bacteria resulted in the reduction or removal of immunostaining of 17 polypeptide bands (Fig. 9, arrows). These bands thus corresponded to proteins which were surface-located and accessible to antibodies. Two of these bands (asterisks, Fig. 9) were not reduced in intensity in similar experiments conducted with sera absorbed with heterologous (A1, A6, A7, A9, T3) serotype envelope preparations (data not shown). This suggests that these polypeptides may be specific to the A2 serotype and are probably surface-located.

\section{Discussion}

Envelopes from $P$. haemolytica and $P$. multocida were isolated successfully and reproducibly by a modification of the method of Witholt et al. (1976) which employed osmotic lysis. This obviated the need to use more damaging physical methods.

Envelopes isolated from $P$. haemolytica biotype A, $P$. haemolytica biotype $\mathrm{T}$ and $P$. multocida could be differentiated by their SDS-PAGE profiles. Furthermore, different isolates of the same $P$. haemolytica $A$ strain always generated very similar SDS-PAGE profiles. $P$. haemolytica $\mathrm{T}$ envelopes gave simpler SDSPAGE profiles which were typified by distorted bands in the high-molecular-mass region. The reason for this is unknown. These results confirm those of Thompson \& Mould (1975), who analysed phenol/acetic acid cell extracts of $P$. haemolytica by SDS-PAGE and showed differences in the profiles of extracts derived from $A$ strains and T strains. Donachie et al. (1984) also showed similarities in A strain extracts produced using sodium salicylate. 

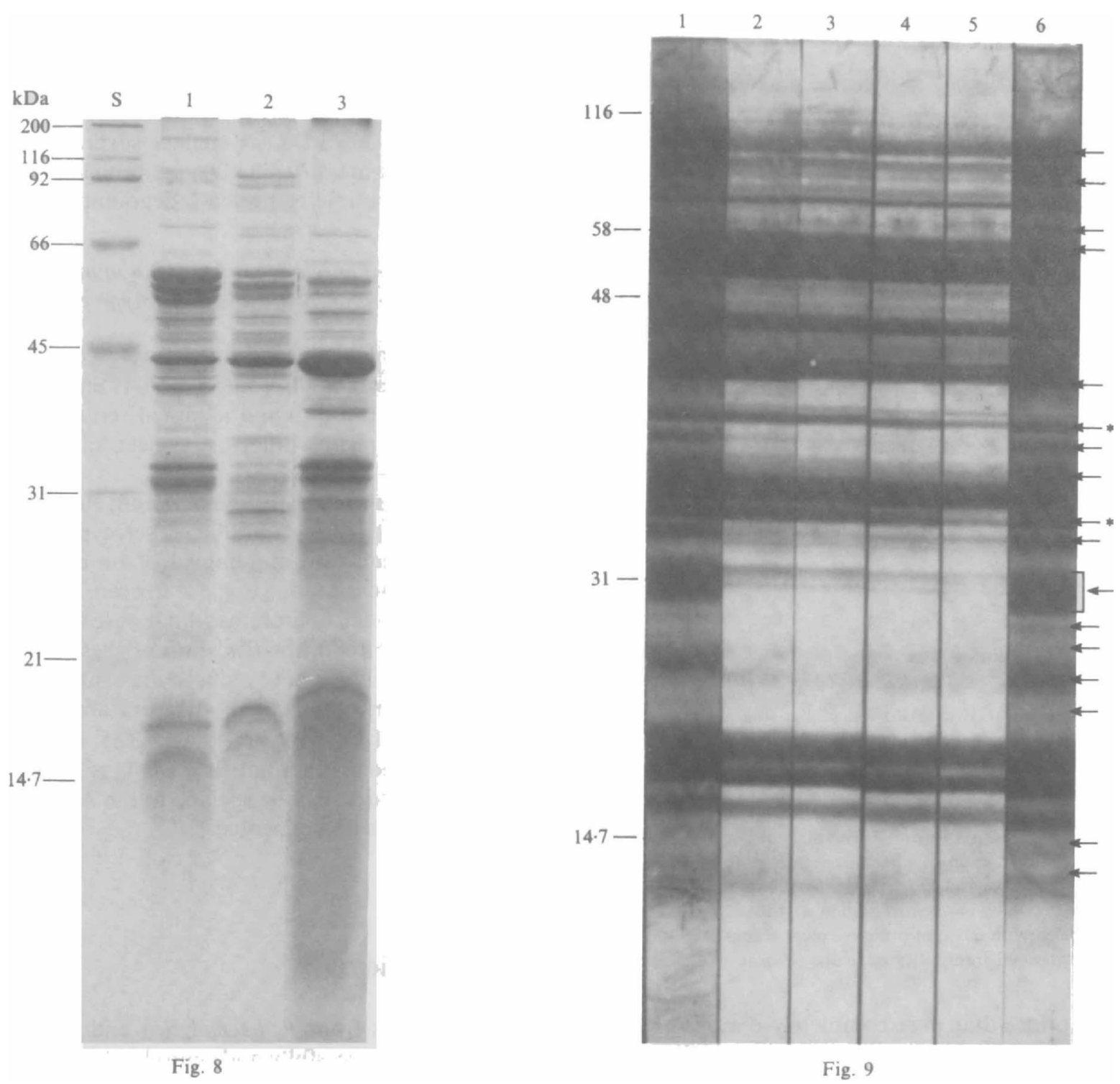

Fig. 8. SDS-PAGE examination of A2 serotype envelopes prepared from cells subjected to proteolytic digestion prior to envelope isolation. Track $S$ contains molecular mass standards. Track 1, A2 envelopes prepared from untreated cells; 2, A2 envelopes produced following treatment of cells with proteinase $\mathrm{K} ; 3, \mathrm{~A} 2$ envelopes produced following treatment of cells with trypsin. All tracks were loaded with $60 \mu \mathrm{g}$ of protein.

Fig. 9. Immunoblotted $A 2$ serotype envelopes probed with anti-A2 serotype envelope serum absorbed with $A 2$ cells. Tracks $S$ contains molecular mass standards. A2 serotypes were probed with the following: tracks 1 and 6, anti-A2 serotype envelope antiserum (AES); 2 , AES absorbed with $\times 1$ concentration A2 serotype cells; 3 , AES absorbed with $\times 2$ concentration A2 serotype cells; 4 , AES absorbed with $\times 4$ concentration A2 serotype cells; 5 , AES absorbed with $\times 8$ concentration A2 serotype cells. See text for explanation of arrows.

$P$. multocida serotype B could be distinguished from the other $P$. multocida serotypes by the presence of a major band at $\sim 33 . \mathrm{kDa}$. Profiles of $P$ multocida $\mathrm{D}$ strains were broadly similar to those reported from atrophic rhinitis-producing strains by Lugtenberg $e t$ al. (1984, 1986).

Sucrose density gradient centrifugation of membranes gave effective separation of proteins into putative inner- and outer-membrane fractions. The separation achieved was broadly similar to that achieved by Squire et al. (1984) and confirmed the differences between $P$. haemolytica biotypes and $P$. multocida serotypes seen using SDS-PAGE of unfractionated membranes.

The criteria used for assigning putative outer-membrane proteins were surface labelling $\left.{ }^{(25} \mathrm{I}\right)$, insolubility in Triton X-100/ $\mathrm{Mg}^{2+}$, specific gravity of $\sim 1.22 \mathrm{~g} \mathrm{~cm}^{-3}$ 
following isopycnic sucrose density gradient separation, absorption of specific antibody by homologous serotype cells and susceptibility to protease digestion in intact cells. The behaviour of several polypeptides did not always meet the above criteria in all types of experiment.

With reference to the standard A2 profile given in Fig. 1 and based on the characteristics of individual polypeptides listed in Table 2, the following polypeptides appear to be located in the outer membrane: bands 4,7 , $9,15,16,22,23,30,33,41,42,43$ and 44 . The following bands were probably not surface-located: bands 8,24 , $28,29,37,38,39$ and 40.

Blotting experiments (data not shown) in which envelopes from selected serotypes of $P$. haemolytica and $P$. multocida were probed with an A2 serotype envelope antiserum detected several common proteins. One noticeable polypeptide band corresponded to a molecular mass of $\sim 89.2 \mathrm{kDa}$ (arrow in Fig. 3). This protein was always found in sucrose density gradient fractions associated with putative outer-membrane proteins. However, it did not appear to radiolabel with ${ }^{125}$ I and antibodies to it were not absorbed from specific antisera using living whole cells. The polypeptide had unusual detergent solubilities in being soluble in Sarkosyl (data not shown) but insoluble in Triton $\mathrm{X}-100 / \mathrm{Mg}^{2+}$. It could, therefore, represent an outer-membrane protein which is not surface-expressed and with somewhat unusual detergent solubility properties.

The purification and characterization of this and other common envelope proteins may lead to an improved understanding of their role in pasteurellosis and of their vaccine potential.

\section{References}

Adlam, C., Knights, J. M., Mugridge, A., Lindon, J. C., Baker, P. W. R., Beesley, J. E., SPacey, B., Craig, G. R. \& Nagy, L. K. (1984). Purification, characterization and immunological properties of the serotype-specific capsular polysaccharide of Pasteurella haemolytica (serotype A1) organisms. Journal of General Microbiology 130, 2415-2426.

Adlam, C., Knights, J. M., Mugridge, A., Lindon, J. C., Williams, J. M. \& BeEsley, J. E. (1985a). Purification, characterization and immunological properties of the serotype-specific capsular polysaccharide of Pasteurella haemolytica (serotype T4) organisms. Journal of General Microbiology 131, 387-394.

Adlam, C., KNights, J. M., Mugridge, A., Lindon, J. C., Williams, J. M. \& BeEsLeY, J. E. (1985b). Purification, characterization and immunological properties of the serotype-specific capsular polysaccharide of Pasteurella haemolytica serotype T15: its identity with the K62 (K2ab) capsular polysaccharide of Escherichia coli and the capsular polysaccharide of Neisseria meningitidis serogroup $\mathrm{H}$. Journal of General Microbiology 131, 1963-1972.

Adlam, C., Knights, J. M., Mugridge, A., Lindon, J. C., Williams, J. M. \& Beesley, J. E. (1986). Purification, characterization and immunological properties of the serotype-specific capsular polysaccharide of Pasteurella haemolytica (serotype A7) organisms. Journal of General Microbiology 132, 1079-1087.

Adlam, C., Knights, J. M., Mugridge, A., Williams, J. M. \& Lindon, J. C. (1987). Production of colominic acid by Pasteurella haemolytica serotype A2 organisms. FEMS Microbiology Letters 42 , 23-25.

BiBERSTEIN, E. L. (1978). Biotyping and serotyping of Pasteurella haemolytica. Methods in Microbiology 10, 253-268.

Donachie, W. D., Gilmour, N. J. L., Mould, D. L. \& Poxton, I. R. (1984). Comparison of cell surface antigen extracts from two serotypes of Pasteurella haemolytica. Journal of General Microbiology 130, $1209-1216$.

Fodor, L., Varga, J., Hajtos, J., Donachie, W. \& Gilmour, N. J. L. (1988). Characterisation of a new serotype of $P$. haemolytica isolated in Hungary. Research in Veterinary Science 44, 399.

Gilmour, N. J. L., Martin, W. B., Sharp, J. M., Thompson, D. A., Wells, P. W. \& DonaChIE, W. (1983). Experimental immunisation of lambs against pneumonic pasteurellosis. Research in Veterinary Science 35, 80-86.

LAEMMLI, U. K. (1970). Cleavage of structural proteins during the assembly of the head of bacteriophage T4. Nature, London 227, 680 685.

Lugtenberg, B., van Boxtel, R. \& De Jong, M. (1984). Atrophic rhinitis in swine: correlation of Pasteurella multocida pathogenicity with membrane protein and lipopolysaccharide patterns. Infection and Immunity 46, 48-54.

LugtenberG, B., Van Boxtel, R., Evenberg, D., DE Jong, M., Storm, P. \& FrIK, J. (1986). Biochemical and immunological characterization of cell surface proteins of Pasteurella multocida strains causing atrophic rhinitis in swine. Infection and Immunity 52 , 175-182.

OsboRN, M. J. (1963). Studies on the Gram-negative cell wall, I. Evidence for the role of 2-keto-3-deoxyoctonate in the lipopolysaccharide of Salmonella typhimurium. Proceedings of the National Academy of Sciences of the United States of America 50, 499-506.

Osborn, M. J., Gander, J. E., Parisi, E. \& Carson, J. (1972). Mechanism of assembly of the outer membrane of Salmonella typhimurium (isolation and characterization of cytoplasmic and outer membrane). Journal of Biological Chemistry 247, 3962-3972.

OWEN, P. (1985). Crossed immunoelectrophoresis in the study of outer membrane antigens. In Enterobacterial Surface Antigens: Methods for Molecular Characterisation, pp. 207-242. Edited by T. K. K. Korhonen, E. A. Dawes \& P. H. Makela. Amsterdam: Elsevier.

SchnatTMAN, C. A. (1973). Outer membrane proteins of Escherichia coli. I. Effect of preparation conditions on the migration of protein in polyacrylamide gels. Archives of Biochemistry and Biophysics 157, $541-552$.

SQuire, P. G., SMiley, D. W. \& CRoskell, R. B. (1984). Identification and extraction of Pasteurella haemolytica membrane proteins. Infection and Immunity 45, 667-673.

Thompson, D. A. \& Mould, D. L. (1975). Protein electrophoretic pattern of Pasteurella haemolytica. Research in Veterinary Science 18 , 342-343.

Towbin, H., Staehelin, T. \& GoRdon, J. (1979). Electrophoretic transfer of proteins from polyacrylamide gels to nitrocellulose sheets: procedure and some applications. Proceedings of the National Academy of Sciences of the United States of America 75, 4350-4354.

Witholt, B., Boekhaut, M., Brock, M., Kingma, J., Van HeeriKHUIZEN, H. \& DE LEIJ, L. (1976). An efficient and reproducible procedure for the formation of spheroplasts from variously grown Escherichia coli. Analytical Biochemistry 74, 160-170. 